\title{
PENERAPAN POMPA HIDRAM METODE PARALEL DI DESA PUNGGUK BERINGIN BENGKULU TENGAH
}

\section{APPLICATION OF PARALLEL METHODS HYDRAULIC RAM IN PUNGGUK BERINGIN CENTRAL BENGKULU}

\author{
Oleh: \\ Irkhos $^{\text {l) }}$, Suhendra ${ }^{1)}$, dan Sukisno ${ }^{2)}$ \\ 1) Jurusan Fisika FMIPA Universitas Bengkulu \\ 2) Program Studi Ilmu Tanah FP Universitas Bengkulu \\ irkhosazir@gmail.com
}

\begin{abstract}
The program is implemented in Pungguk Beringin Merigi Kelindang Bengkulu Tengah. The purpose of this program is to provide the knowledge and skills of rural communities Pungguk Beringin on utilization Hydraulic ram. Participants were representatives of community activities. The solution provided is the application of Parallel Methods Hydraulic ram. Through this program generated installation Hydraulic ram diameter of 2 inches with 10 liters of effluent water discharge to drain the water to a height of 50 meters by 150 meters.
\end{abstract}

Keywords: Hydraulic ram pump, Parallel Methods, Pungguk Beringin

\section{PENDAHULUAN}

Kabupaten Bengkulu Tengah terletak pada ketinggian 0-541 $\mathrm{m}$ di atas permukaan laut (dpl) dengan topografi bergelombang dan berbukit dengan derajat kelerengan antara 5$35^{\circ}$. Wilayah yang relatif datar dengan tingkat kelerengan rata-rata $5^{\circ}$ terletak di wilayah Kecamatan Pondok Kelapa. Lokasi dengan titik tertinggi hingga $541 \mathrm{~m}$ di atas permukaan laut (dpl) berada di kawasan hutan lindung yang berbatasan dengan Kabupaten Kepahiang. Sedangkan daerah terendah terletak di wilayah Kecamatan Pondok Kelapa dengan ketinggian 0-15 mdpl. Berdasarkan jenis tanahnya, Kabupaten Bengkulu Tengah sebagian berjenis tanah assosiasi lotosol dan andosal sebesar 30,46 \%, regogol sebesar 30,10\%, podsolik merah kuning (PMK) sebesar 13,14 \%, asosiasi podsolik coklat dan litosol sebesar 7,09 \%, alluvial sebesar 7,06 \%, asosiasi andosol regosol sebesar 6,07\%, latosol sebesar 5,66 \% dan organosol sebesar 0,42 \%. Kabupaten Bengkulu Tengah memiliki banyak sungai yang berhulu di sisi timur Bukit Barisan dan mengalir ke Samudera Indonesia (BPS, 2013).

Salah satu desa yang berada di Kecamatan Merigi Kelindang Kabupaten Bengkulu Tengah yang letaknya cukup tinggi dpl adalah Desa Pungguk Beringin. Desa Pungguk Beringin merupakan dataran tinggi yang terletak lebih kurang $500 \mathrm{~m}$ dpl. Pungguk 
Beringin terdiri dari dua dusun yang ditempati oleh 102 kepala keluarga. Sebagian besar penduduk (99\%) bermata pencarian sebagai petani karet dan kopi. Sedangkan jenis tanaman palawija tidak berkembang disebabkan oleh kesulitan air (Tabel 1). Untuk memenuhi kebutuhan beras, sayur-sayuran dan bahan makanan pokok, penduduk Desa Pungguk Beringin harus membelinya dari luar kecamatan.

Transportasi yang cukup jauh semakin memperparah pasokan kebutuhan makanan pokok warga. Meskipun sebagian besar penduduk bermata pencaharian sebagai petani karet dan kopi, namun sektor pertanian belum optimal meningkatkan taraf hidup masyarakat. Penyebab utamanya adalah belum maksimalnya hasil pertanian karena sulitnya mendapatkan air untuk pertanian. Untuk keperluan minum, mandi dan kebutuhan sehari-hari, masyarakat menampung air hujan dan jika pada musim kemarau masyarakat harus menuruni lembah untuk mencapai sungai.

Tabel 1. Jumlah Keluarga, Persentase Petani, dan Komoditi Unggulan Di Kecamatan Merigi Kelindang

\begin{tabular}{clccc}
\hline No & \multicolumn{1}{c}{ Desa } & Jumlah KK & Jml Petani(\%) & Komoditi Unggulan \\
\hline 1 & Bajak II & 168 & 97 & Karet \\
2 & Jambu & 332 & 90 & Kopi \\
3 & Penembang & 212 & 95 & Kopi \\
4 & Lubuk Unen & 340 & 75 & Padi \\
5 & Pungguk Ketupak & 102 & 95 & Kopi \\
6 & Pungguk Beringin & 102 & 99 & Karet \\
7 & Kelindang & 128 & 99 & Karet \\
8 & Ulak Lebar & 105 & 98 & Karet \\
9 & Taba Durian Sebakul & 133 & 100 & Karet \\
10 & Talang Ambung & 57 & 99 & Kopi \\
11 & Lubuk Unen II & 164 & 98 & Kopi \\
12 & Padang Kedeper & 75 & 99 & Karet \\
13 & Kelindang Atas & 203 & 97 & Padi \\
\hline
\end{tabular}

Sumber : BPS Kabupaten Bengkulu Tengah Tahun 2012

Tanaman padi dan tanaman palawija terus megalami penurunan hasil dan bahkan gagal panen. Penurunan hasil panen tanaman padi dan palawija ini juga disebabkan semakin meningkatnya jumlah lahan yang dialihkan fungsinya menjadi perkebunan kopi dan karet. Tanaman padi dan palawija sering mengalami gagal panen karena pasokan air tidak mencukupi. Berdasarkan data BPS 2012, produksi padi mengalami penurunan dari 41.437 ton tahun 2009 berkurang menjadi 37.179 ton 2010 dan terus berkurang menjadi 34.798 ton 2011. Hal yang sama juga terjadi pada jenis tanaman palawija lainnya.

Sumber air untuk keperluan sehari-hari dan untuk keperluan pertanian adalah air hujan dan sungai (Tabel 2). Curah hujan tertinggi terjadi pada bulan November dengan jumlah hari hujan pertahun rata-rata 140 hari. Berdasarkan data BPS, di Kabupaten Bengkulu Tengah hingga tahun 2012 belum memiliki Perusahaan Daerah Air Minum 
(PDAM). Pemerintah daerah membentuk Badan Layanan Umum Air Minum (BLUAM) yang mampu mendistribusikan air dengan kapasitas 532.014 meter $^{3}$, hanya sebagian kecil masyarakat yang mendapatkan pasokan air dan belum dapat menjangkau masyarakat yang berada di dataran yang lebih tinggi seperti Kecamatan Merigi Kelindang yang merupakan lokasi target pengabdian.Sebagian besar masyarakat khususnya masyarakat Desa Pungguk Beringin harus berjuang setiap hari menuruni lembah menuju sungai untuk mendapatkan air.

Tabel 2. Sumber Air Minum per Desadi Kecamatan Merigi Kelindang

\begin{tabular}{clll}
\hline No & \multicolumn{1}{c}{ Desa } & Sumber Air Minum & Fasilitas Buang Air Besar \\
\hline 1 & Bajak II & Sungai & Jamban Umum \\
2 & Jambu & Sungai & Jamban Sendiri \\
3 & Penembang & Sungai & Jamban Bersama \\
4 & Lubuk Unen & Sumur & Sungai \\
5 & Pungguk Ketupak & Sumur & Sungai \\
6 & Pungguk Beringin & Air Hujan & Sungai \\
7 & Kelindang & Sumur & Sungai \\
8 & Ulak Lebar & Sumur & Sungai \\
9 & Taba Durian Sebakul & Sungai & Sungai \\
10 & Talang Ambung & Mata Air & Sungai \\
11 & Lubuk Unen II & Mata Air & Sungai \\
12 & Padang Kedeper & Sungai & Jamban Bersama \\
13 & Kelindang Atas & Sumur & Sungai \\
\hline
\end{tabular}

Sumber : BPS Kabupaten Bengkulu Tengah Tahun 2013

Sungai-sungai yang berada di Desa Pungguk Beringin letaknya lebih rendah $50 \mathrm{~m}$ dan berjarak sekitar $200 \mathrm{~m}$ dari pemukiman dan lahan pertanian yang berhulu di sisi timur bukit barisan dan bermuara di Samudera Hindia (BPS, 2012). Pada musim kemarau, debit terendah sungai yang ada di dekat Desa Pungguk Beringin lebih kurang $1 \mathrm{~m}^{3} / \mathrm{detik}$. Air yang bersumber dari sungai tersebut jika dimanfaatkan akan mencukupi kebutuhan masyarakat sehari-hari maupun untuk keperluan pertanian.

Menurut Ireng dan Julian (2004), kebutuhan air keperluan sehari-hari lebih kurang 45 liter/orang dalam satu hari, jika dihitung keperluan untuk 102 KK di Desa Pungguk Beringin dengan asumsi setiap $\mathrm{KK}$ rata-rata memiliki empat anggota keluarga maka kebutuhan air untuk keperluan sehari-hari masyarakat lebih kurang 45 liter x (102 x 5) orang atau 22.950 liter/hari. Ketersediaan listrik di Kecamatan Merigi Kelindang masih belum merata. Berdasarkan data BPS, penggunaan listrik rata-rata berkisar $50 \%$ dari jumlah Kepala Keluarga (Tabel 3). Pasokan listrik yang belum optimal juga berakibat pada minimnya penggunaan listrik sebagai sumber energi pompa listrik untuk mengalirkan air dari tempat yang lebih rendah. 
Tabel 3. Jumlah Pengguna Listrik di Kecamatan Merigi Kelindang

\begin{tabular}{clc}
\hline No & \multicolumn{1}{c}{ Desa } & Persentase KK Pengguna Listrik \\
\hline 1 & Bajak II & 44,64 \\
2 & Jambu & 90,36 \\
3 & Penembang & 40,09 \\
4 & Lubuk Unen & 29,41 \\
5 & Pungguk Ketupak & 35,29 \\
6 & Pungguk Beringin & 39,22 \\
7 & Kelindang & 57,03 \\
8 & Ulak Lebar & 7,62 \\
9 & Taba Durian Sebakul & 90,23 \\
10 & Talang Ambung & 0 \\
11 & Lubuk Unen II & 41,26 \\
12 & Padang Kedeper & 33,33 \\
13 & Kelindang Atas & 19,70 \\
\hline
\end{tabular}

Mitra yang dihadapkan permasalahan kesulitan air yang cukup ekstrim dan telah berlangsung lama serta posisi topografi yang tinggi jika dibandingkan dengan desa-desa lainnya di Kecamatan Merigi Kelindang diharapkan mampu menjadi inspirasi bagi masyarakat di Kecamatan Merigi Kelindang yang menghadapi permasalahan yang sama.

Hasil survey yang telah dilaksanakan di Desa Pungguk Beringin yang merupakan lokasi target pengabdian, ada beberapa permasalahan dasar yang dihadapi oleh masyarakat yaitu :

1. Kesulitan air untuk memenuhi kebutuhan sehari-hari,

2. Sedikitnya persentase lahan yang memiliki ketersediaan air yang cukup untuk tanaman palawija untuk kebutuhan sehari-hari,

3. Belum meratanya pasokan listrik untuk memenuhi keperluan masyarakat untuk penerangan maupun kebutuhan energi untuk perkakas/peralatan dalam aktifitas masyarakat.

Sementara kemampuan masyarakat dalam menyelesaikan permasalahan sangat terbatas disebabkan minimnya pengetahuan dan keterampilan. Berdasarkan diskusi dengan masyarakat diketahui bahwa permasalan prioritas yang memerlukan perhatian mendesak adalah kesulitan air untuk kebutuhan sehari-hari dan pertanian.

Kesulitan air untuk memenuhi kebutuhan sehari-hari dan terlebih lagi untuk pertanian selalu dirasakan oleh masyarakat Kecamatan Merigi Kelindang khususnya Dusun I dan Dusun II yang berada di Desa Pungguk Beringin talah berlangsung bertahuntahun. Sungai yang melintasi Desa Pungguk Beringin berada lebih rendah dari pemukiman masyarakat. Untuk mencapai sungai, penduduk harus menempuh jarak lebih kurang $200 \mathrm{~m}$ kemudian turun lebih kurang $50 \mathrm{~m}$ menuju sungai. Kondisi ini menyebabkan penduduk tidak dapat memanfaatkan air sungai secara optimal untuk keperluan sehari-hari serta 
untuk pertanian. Sedangkan sumur yang digali di pemukiman masyarakat tidak ditemukan air hingga kedalaman puluhan meter.

Pada tahun 2006, masyarakat Desa Pungguk Beringin mendapat bantuan pengadaan instalasi pipa paralon dari pemerintahan setempat untuk mengalirkan air sungai ke pemukiman, namun usaha tersebut belum mampu mengalirkan air ke pemukiman karena posisi pemukiman lebih tinggi dariposisi sungai. Untuk mengailirkan air sungai yang berada $50 \mathrm{~m}$ di bawah desa dan lahan pertanian dapat dilakukan dengan menggunakan mesin pompa, namun harus mengeluarkan biaya yang tidak sedikit untuk bahan bakar ataupun listrik. Di sisi lain, dengan keadaan topografi yang bergelombang, posisi Desa Pungguk Beringin yang relatif tinggi, maka kondisi ini cukup potensial untuk dikembangkan Pembangkit Listrik Tenaga Mikro Hidro (PLTMH) jika sumber air memadai di sebuah ketinggian.

Berdasarkan informasi dari aparatur Desa Pungguk Beringin, usaha dalam memenuhi kebutuhan air untuk keperluan sehari-hari dan pertanian telah sering dilakukan baik oleh pemerintah daerah maupun swadaya masyarakat. Namun usaha yang telah dilakukan belum mampu memberi solusi atas kesulitan akan air.Air sebagai komponen sumber daya alam yang sangat penting maka harus dipergunakan untuk sebesar-besarnya bagi kemakmuran rakyat. Hal ini berarti bahwa penggunaan air untuk berbagai manfaat dan kepentingan harus dilakukan secara bijaksana dengan memperhitungkan kepentingan generasi masa kini dan masa depan. Untuk itu air perlu dikelola agar tersedia dalam jumlah yang aman, baik kuantitas maupun kualitasnya, dan bermanfaat bagi kehidupan dan perikehidupan manusia serta makhluk hidup lainnya agar tetap berfungsi secara ekologis, guna menunjang pembangunan yang berkelanjutan (Edward, 2006).

Kesulitan air yang telah berlangsung selama bertahun-tahun hingga saat ini di Desa Pungguk Beringin dapat diatasi dengan berbagai caraantara lain :

1. Menggunakan pompa berbahan bakar minyak (BBM) atau listrik,

2. Memanfaatkan gaya potensial dan grafitasi,

3. Membuat bak penampung air hujan,

4. Memanfaatkan teknologi sederhana yaitu pompa hidram.

Pompa hidram adalah pompa tanpa bahan bakar dan juga tidak menggunakan motor listrik untuk menyedot air (Hari dan Heru, 2006). Pompa hidram bekerja dengan menggunakan tenaga air itu sendiri, yaitu efek water hammer yang terjadi karena ada perbedaan ketinggian. Pompa hidram dapat mengalirkan air ke lokasi yang lebih tinggi (Irkhos, 2012). Pasokan air 0,7lt/detik/Ha sudah terpenuhi dengan menggunakan pompa hidram dengan diameter 2 inchi (Suarda dan Irawan, 2008; dan Yeni dkk, 2009). Besarnya kenaikan tekanan ketinggian air dapat dihitung menggunakan persamaan:

$$
\Delta H p=\frac{c\left(v_{1}-v_{2}\right)}{g}
$$

Dimana: 
$\Delta \mathrm{Hp}=$ Kenaikan ketinggian air oleh tekanan (m)

$\mathrm{c}=$ Kecepatan gelombang suara dalam air $\left(\frac{\mathrm{m}}{\mathrm{s}}\right)$

$v_{1}=$ Kecepatan air sebelum katup menutup $\left(\frac{\mathrm{m}}{\mathrm{s}}\right)$

$v_{2}=$ Kecepatan air sesudah katup menutup $\left(\frac{\mathrm{m}}{\mathrm{g}}\right)$

$\mathrm{g}=$ Kecepatan grafitasi $\left(\frac{\mathrm{m}}{\mathrm{s}^{2}}\right)$

Efisiensi pompa hidram dapat dihitung menggunakan persamaan D'Aubuisson:

$\eta A=\frac{q h}{(Q+q) H} \times 100 \%$

Dimana:

$\eta \mathrm{A}=$ Efisiensi pompa hidram $(\%)$

$\mathrm{q}=$ Debit hasil $\left(\frac{\mathrm{m}^{3}}{\mathrm{~s}}\right)$

$Q=$ Debit limbah $\left(\frac{\mathrm{m}^{3}}{\mathrm{~s}}\right)$

$\mathrm{h}=$ Ketinggian air keluar (m)

$\mathrm{H}=$ Ketinggian air masuk $(\mathrm{m})$

Prinsip kerja dari pompa Hidram dapat dilihat dari gambar irisan pompa hidram. Bagian kunci dari Hidram adalah dua buah klep, yaitu: klep pembuangan dan klep penghisap. Air masuk dari terjunan melalui pipa $\mathrm{B}$, klep pembuangan terbuka sedangkan klep penghisap tertutup (Gambar 2).

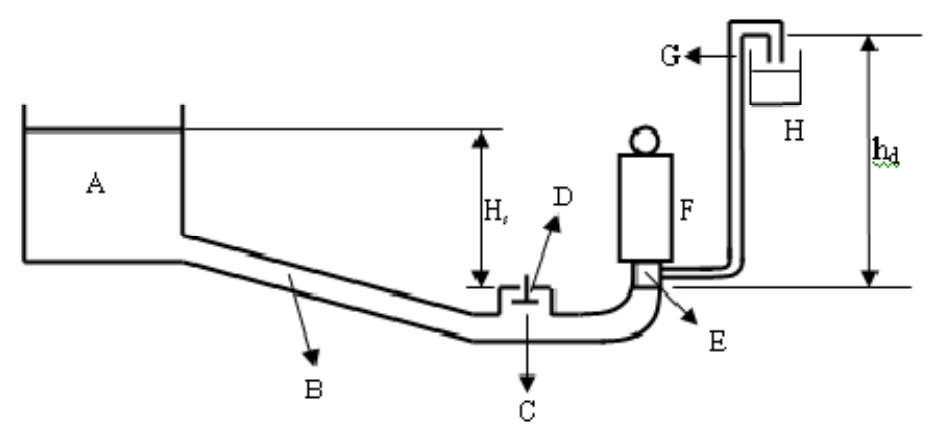

Gambar 2. Skema instalasi pompa hidram

Air yang masuk memenuhi rumah pompa mendorong ke atas klep pembuangan hingga menutup. Dengan tertutupnya klep pembuangan mengakibatkan seluruh dorongan air menekan dan membuka klep penghisap dan air masuk memenuhi ruang dalam tabung kompresi di atas klep penghisap. 
Pada volume tertentu pengisian air dalam tabung kompresi optimal, massa air dan udara dalam tabung kompresi akan menekan klep penghisap untuk menutup kembali, pada saat yang bersamaan sebagian air keluar melalui pipa G. Dengan tertutupnya kedua klep, maka aliran air dalam rumah pompa berbalik berlawanan dengan aliran air masuk, diikuti dengan turunnya klep pembuangan karena arah tekanan air tidak lagi ke klep pembuangan tetapi berbalik ke arah pipa input B. Hantaman -ram-palu air (water hammer) itu terjadi, dimana air dengan tenaga gravitasi dari terjunan menghantam arus balik tadi, 2/3 debit keluar lubang pembuangan, sementara yang $1 / 3$ debit mendorong klep penghisap masuk ke dalam tabung pompa sekaligus mendorong air yang ada dalam tabung pompa untuk keluar melaui pipa output G. Begitulah energi hantaman yang berulang-ulang mengalirkan air ke tempat yang lebih tinggi.Kegiatan pengabdian bagi masyarakat ini bertujuan untuk meningkatkan pengetahuan masyarakat tentang pompa hidram serta memberikan manfaat bagi masyarakat sebagai solusi kesulitan air untuk kebutuhan sehari-hari.

\section{METODE PENGABDIAN}

Ada tiga tahapan yang ditawarkan untuk mendukung realisasi program, [1]Sosialisasi teknologi sederhana pompa hidram, [2] pelatihan pembuatan pompa hidram dan instalasi pipa, dan [3] Pemasangan pompa hidram dan perawatan.Pada tahapan sosialisasi dilakukan pengenalan tentang teknologi sederhana pompa hidram. Kegiatan sosialisasi dilakukan dalam bentuk penyuluhan dengan peserta terdiri dari kepala dusun I dan II, perangkat dusun I dan II beserta perwakilan Karang Taruna dusun I dan II masingmasing 10 orang. Pada tahapan pelatihan peserta dilatih tentang pembuatan pompa hidram yang meliputi pengenalan alat dan bahan, pelatihan instalasi pipa serta perhitungan kebutuhan air untuk setiap kepala keluarga dan luas lahan pertanian.

Peserta pelatihan terdiri dari kepala dusun I dan II, perangkat dusun I dan II beserta perwakilan Karang Taruna dusun I dan II. Setelah mengikuti kegiatan pelatihan, peserta mampu membuat pompa Hidram dan mengetahui spesifikasi pompa sesuai dengan jumlah kebutuhan air. Tahapan terakhir pemasangan pompa dan jaringan pipa. Berdasarkan analisis kebutuhan air serta penentuan spesifikasi pompa, instalasi pipa serta bak penampungan dibangun secara permanen sehingga dapat langsung dimanfaatkan untuk memenuhi kebutuhan masyarakat. Peserta terdiri dari kepala dusun I dan II, perangkat dusun I dan II beserta perwakilan Karang Taruna dusun I dan II.

\section{HASIL DAN PEMBAHASAN}

Tim pengabdian telah melakukan penyuluhan tentang teknologi tepat guna pompa hidram, metode pemasangan, perawatan dan analisis kebutuhan air. Pada kegiatan ini telah diundang sebagai peserta kegiatan yaitu perwakilan masyarakat Pungguk Beringin. 


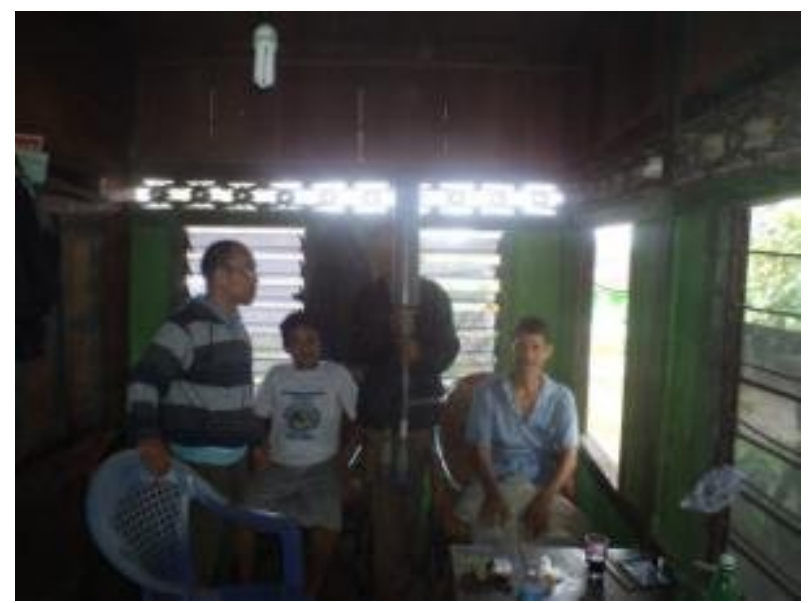

Gambar 3. Sosialisasi pemanfaatan pompa hidram

Penyuluhan dan pelatihan diberikan agar peserta memiliki pengetahuan dan pengalaman langsung dalam pemanfaatan pompa hidram. Peserta kegiatan penyuluhan dan pelatihan diberikan blueprint metode pemanfaatan pompa hidram, dari kegiatan ini juga dihasilkan pompa hidram yang digunakan oleh warga.

Pompa hidram hidram yang telah dibuat berukuran 2 inci diaplikasikan untuk mengalirkan air dari sumber air yang berjarak lebih kurang $250 \mathrm{~m}$ dari pemukiman warga. Tahapan Instalasi Pompa Hidram terdiri dari : pembuatan bendungan air masukan, pembuatan kolam penampungan air keluaran, pembuatan dudukan pompa hidram, pemasangan pompa hidram, pemasangan pipa masukan dan pemasangan pipa keluaran (Gambar 4).

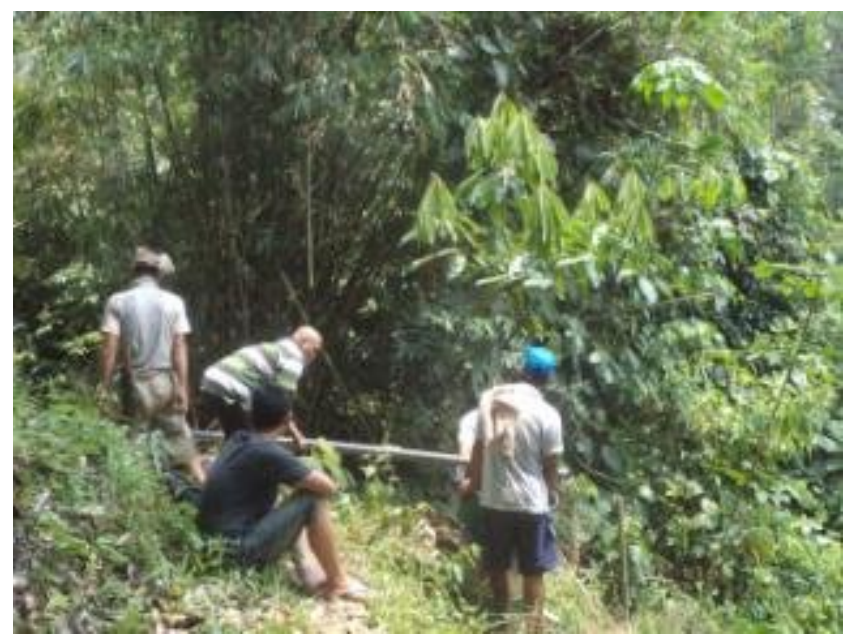

Gambar 4. Pemasangan jaringan pipa masukan 
Pipa masukan dengan ukuran diameter 2 inci dipasang dari sumber air menuju bak penampungan masukan yang berjarak lebih kurang $50 \mathrm{~m}$ (Gambar 5). Air yang ditampung di bak penampungan masukan kemudian dialirkan ke pompa hidram yang berjarak lebih kurang $50 \mathrm{~m}$.

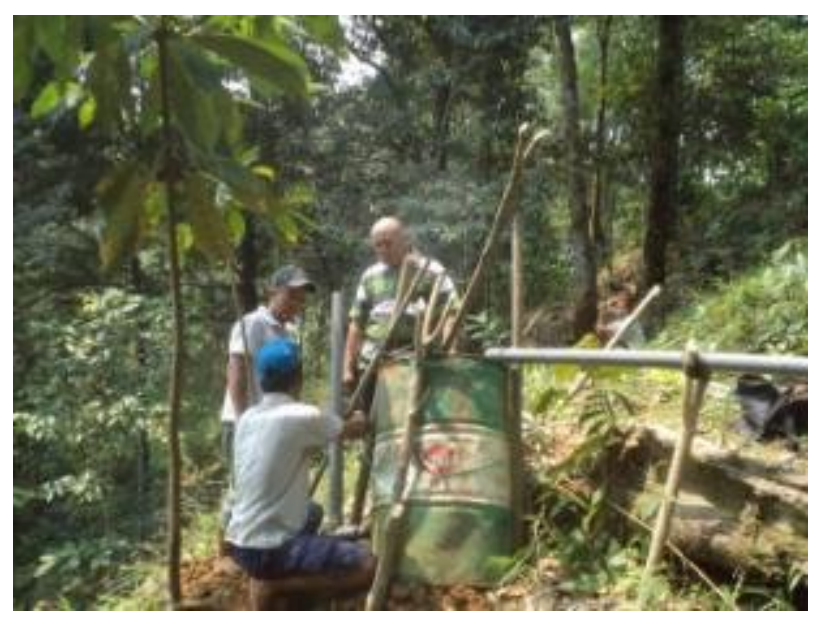

Gambar 5. Bak penampungan masukan

Bak penampungan masukan terbuat dari drum yang dapat dipindah-pindahkan ke lokasi yang lebih stabil. Air masukan harus ditampung terlebih dahulu di bak penampungan agar air yang akan dialirkan ke pompa hidram menjadi konstan debitnya. Pompa hidram harus ditempatkan sesuai dengan analisis kebutuhan air dan kondisi kemiringan lokasi (Gambar 6).

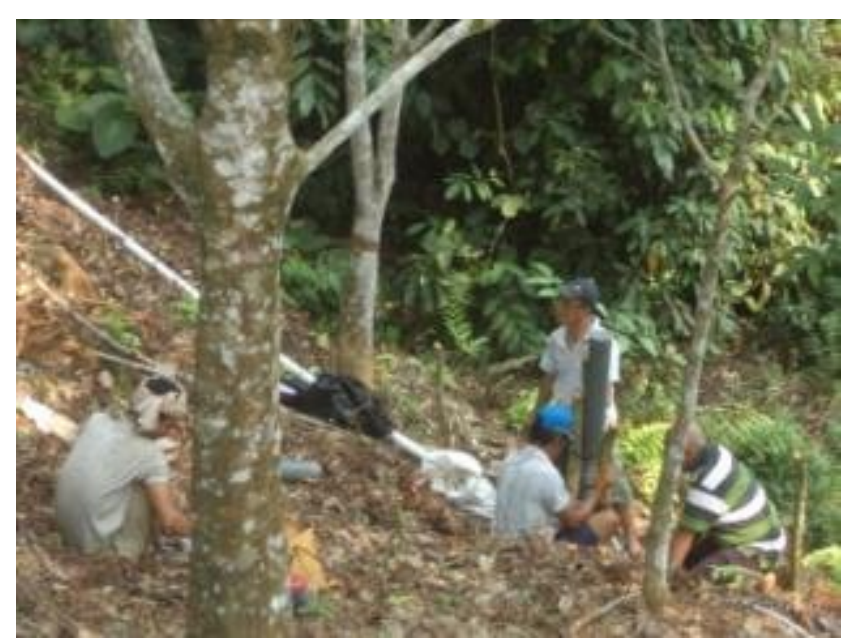

Gambar 6. Lokasi penempatan pompa hidram

Pompa hidram 2 inci mampu menyalurkan air dengan perbandingan ketinggian sumber air ke pompa dan pompa ke bak penampungan lebih kurang 1:3. Dengan ketinggian sumber air 15 meter maka pompa yang dirancang mampu mengalirkan air 
setinggi $50 \mathrm{~m}$. Debit yang dihasilkan lebih kurang 10 liter tiap menit (Gambar 7). Kebutuhan air masyarakat dalam satu hari harus dihitung dengan cermat agar air yang disalurkan sesuai dengan kebutuhan masyarakat. Jika volume air yang dialirkan dalam satu hari lebih besar dari kebutuhan masyarakat untuk satu hari maka akan terjadi kelebihan air. Begitu pula sebaliknya, jika volume air yang dialirkan dalam satu hari lebih kecil dari kebutuhan masyarakat dalam satu hari maka akan terjadi kekurangan air.

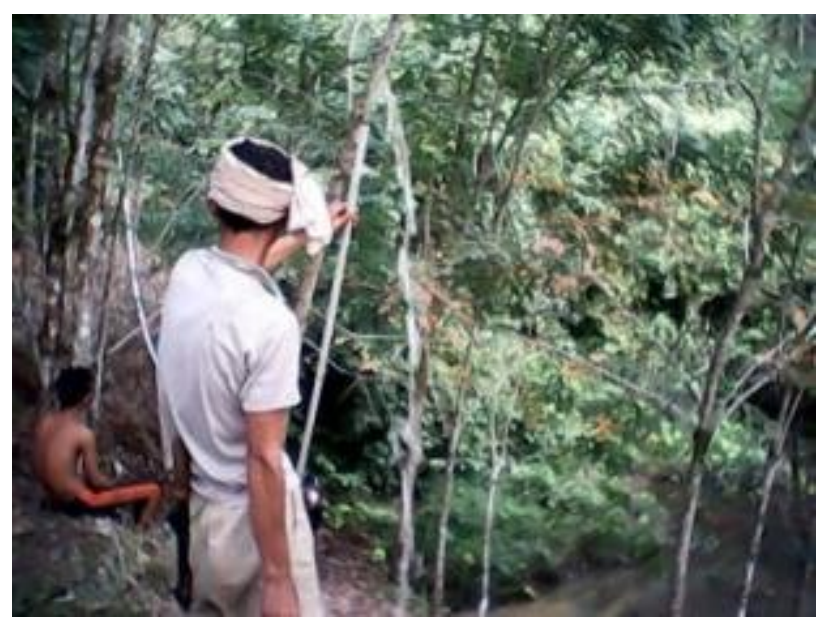

Gambar 7. Air keluaran pompa hidram

Ketahanan pompa hidram tergantung kepada perawatan. Perawatan harus dilakukan secara teratur. Sumber air yang digunakan harus dijaga agar terbebas dari sampah dengan cara membuat saringan, Kestabilan aliran yang akan disalurkan dari suber air ke pompa hidram dapat dicapai dengan cara mengalirkan air sumber ke bak terlebih dahulu, kemudian dialirkan dari bak ke pompa hidram.

\section{KESIMPULAN DAN SARAN}

Kegiatan pengabdian telah berjalan dengan baik meskipun terjadi perubahan jadwal. Teknologi tepat guna pompa hidram metode paralel merupakan salah satu solusi tepat bagi masyarakat yang kesulitan air khususnya daerah yang berada pada dataran tinggi seperti Desa Pungguk Beringin Bengkulu Tengah. Debit air yang mampu dialirkan dari sumber air yang berjarak horizontal $250 \mathrm{~m}$ dan ketinggian vertikal $50 \mathrm{~m}$ menggunakan pompa 2 inci lebih kurang 10 liter tiap menit.

Keberhasilan kegiatan pengabdian pemanfaatan pompa hidram dipengaruhi oleh beberapa hal diantaranya ketersediaan air sumber yang bergantung pada cuaca atau curah hujan, topografi lokasi, serta partisipasi masyarakat. Agar teknologi pompa hidram memberikan manfaat yang lebih besar maka perlu diupayakan kegiatan transfer teknologi 
tepat guna pompa hidram dengan skala yang lebih besar yang mencakup beberapa desa di Kecamatan Merigi Kelindang Bengkulu Tengah.

\section{DAFTAR PUSTAKA}

BPS Benteng, 2013, Bengkulu Tengah Dalam Angka, Karang Tinggi, Bengkulu.

Hari, H dan Heru, D.W., 2006, Rancang Bangun Pompa Hidram Untuk Masyarakat Pedesaan, JAI, BPPT.

Irkhos dkk, 2012, Desain Pompa Hidram Paralon, Laboratorium Fisika FMIPA UNIB.

Irkhos dkk, 2011, Pemanfaatan Pompa Hidram Sebagai Solusi Kesulitan Air di Kecamatan Bermani Ulu Raya Kabupaten Rejang Lebong, Jurnal Darma Raflesia LPPM UNIB.

Ireng, S. A dan Julian, A, 2004, Pompa Hidram Untuk Kebutuhan Petani di Daerah Berbukit, Jurnal Traksi, 2004, Vol. 2, No. 1.

Suarda, M dan Irawan, IKG, 2008, Kajian Eksperimental Pengaruh Tabung Udara pada Head Tekanan Pompa Hidram, Jurnal Ilmiah Teknik Mesin, CAKRAM, Vol. 2 No.1 pp:10-14.

Yeni, H dkk, 2009, Panjang Pipa Inlet Terhadap Efisiensi Pompa Hidram, Jurnal Dinamika, Teknik Sipil UMS. 